\title{
Educators enacting online learning support roles in remote educational experiences
}

\author{
Peter Samuelson Wardrip ${ }^{1}$ (D)
}

Accepted: 7 November 2020 / Published online: 23 November 2020

(c) Association for Educational Communications and Technology 2020

\begin{abstract}
Schools across the world have been shifting to remote learning options as the COVID-19 pandemic continues to spread. As educators continue to facilitate remote learning, how can they practically think about adapting their instructional practice? Drawing on the work of $\mathrm{Nacu}$ et al. (Designing for 21st century learning online: A heuristic method to enable educator learning support roles. Educational Technology Research and Development, 66(4), 1029-1049, 2018), this paper introduces pedagogical roles educators could consider in remote environments and a heuristic evaluation method to focus on how those moves might relate to the technologies they are using. In short, this paper is a response to Nacu et al. (2018) from a practice perspective.
\end{abstract}

Keywords Remote learning · Online learning $\cdot$ Pedagogy $\cdot$ Instructional practice

Schools across the United States have been shifting to remote learning ${ }^{1}$ options as the COVID-19 pandemic continues to spread. Thirty-five of the fifty largest school districts in the United States opted for at least some form of remote learning to start the 2020 2021 school year (Cleveland 2020). Across the world, 190 countries have experienced complete or partial shutdown of place-based schooling options (World Bank 2020). And this is not just impacting formal education. For example, significant numbers of museums have sought to recreate their programs or develop new programs that can be facilitated remoted (e.g. ASTC 2020). As we are experiencing this shift to remote learning, we see the continued importance of the role of educators as well as the potential need to shift their instructional practice (Itow 2020). As educators continue to facilitate remote learning, how can they practically think about adapting their instructional practice? Drawing on the work of $\mathrm{Nacu}$ et al. (2018), this paper introduces pedagogical roles educators could consider in

\footnotetext{
${ }^{1}$ While remote learning for many during this period has meant "online learning," I will use the term remote learning to acknowledge that some school districts and learning organizations, either by choice or circumstance, have offered other forms of learning not mediated by a computational device (like a packet of worksheets, for example).
}

Peter Samuelson Wardrip

wardrip@wisc.edu

1 University of Wisconsin Madison, Madison, WI, USA 
Table 1 Online learning support roles (OLSR) framework

\begin{tabular}{ll}
\hline Online learning support role & Definition \\
\hline Audience & View what youth are doing online \\
Encourager & $\begin{array}{l}\text { Provide grads, ratings, badges, or other formal assessments } \\
\text { Exhibit personal approachability/friendship/mentorship, including social } \\
\text { posts. Off-topic conversation }\end{array}$ \\
Instructor & $\begin{array}{c}\text { Directly teach a concept or skill or provide an assignment. Provide prompts } \\
\text { and/or feedback to further student thinking or work }\end{array}$ \\
Learning broker & Connect youth with learning opportunities (people, activities, etc.) \\
Model & Share own creative work/process \\
Monitor & Impose or suggest rules of behavior online (language, behavior, plagiarism, \\
& etc.) \\
Promoter & Showcase youth participant work \\
Resource provider & Provide learning resources (example of work, how-to guides, link to sites, \\
& etc.)
\end{tabular}

online environments. In addition, using a heuristic evaluation method, the paper also makes the connection between the pedagogical roles and the technologies being used.

\section{Pedagogical strategies for online instruction}

What pedagogical strategies can educators employ to support learning remotely? Building on previous work (Nacu et al. 2016), Nacu and colleagues introduce ten Online Learning Support Roles (OLSR). We can see these in Table 1. The OLSRs can provide educators with thinking tools for designing their learning experiences as well as guidance for reflection after facilitating lessons. In particular through designing learning activities, educators can make intentional decisions and seek to vary the ways in which they support learners through OLSRs. In the reflection on their learning activities, educators can consider the extent to which they enacted particular roles and how those roles supported their goals for learning.

\section{Heuristic evaluation}

To explore the relationship between the OLSR framework and the features of the system, the researchers employed heuristic evaluation. This well-known method was developed almost 30 years ago to find usability problems in computer systems. This approach entails involving a small set of evaluators with different expertise to assess how usable a system is based on an agreed upon set of principles, or heuristics. The researchers for this project applied the OLSR framework to various features of their learning platform, iRemix. In doing so, the heuristic evaluation revealed how some features supported different pedagogical roles.

Importantly, as Nacu and colleagues point out, there is an interdependence between the OLSRs that educators play and the features technologies provide to enact those roles (2018). For example, a discussion forum may be more supportive for an educator to serve as an encourager or monitor and less supportive for an educator to be an instructor. An 
awareness of this interdependence creates an alternative way for educators to assess their technology tools. For instance, to what extent can their learning management system support them being a learning broker? Or what technology tools might an educator add to support them being a broker?

\section{Moving forward}

As straightforward as OLSRs are for educators, they create rich and complex opportunities for research and practice. For instance, OLSRs can help guide professional learning experiences for educators. Educators might not just learn how to use a particular technology tool in a professional development program, but instead, explore how that technology tool can support modeling or promoting in their content area. This is partially the argument for technological pedagogical content knowledge; that technology is interdependent with other aspects of our instructional practice (Mishra and Koehler 2006). Moreover, as a pedagogical framework, OLSRs can provide educators with a common language around instruction. It gives words to the pedagogical moves educators might make and allow for the negotiation of what they might look like in practice (Bannister 2015). Common language like this can serve to build community among educators (Wardrip et al. 2015).

Furthermore, while common language may be found, the ways in which educators enact those roles in practice could vary greatly. This could be an area for future research. For instance, encouragement could be conveyed through different technological features (on a discussion board or a video post, for example), could happen at various frequencies or through a variety of phrasings. Understanding the variation could help deepen educators' instructional repertoire as well as ascertain more or less productive means of supporting their learners. Finally, these OLSRs do not need to be solely enacted by educators. Considering the ways that learners fulfill learning support roles themselves could be a strategy for distributing responsibility for the educational experience across all of the learners.

As remote learning continues in various forms around the world, we can look to OLSRs as potential guideposts for educators to support learning in remote settings. Whether we are designers, educators, researchers or a mixture of the three, we can test this framework as a guide for ensuring that our learners are assistant in their educational experiences.

\section{Compliance with ethical standards}

Conflict of interest The author has no potential conflicts of interest.

Research involving human and animals rights The paper presents no research involving human participants and/or animals.

Informed consent Because of the nature of the paper, there was no need for Informed consent.

\section{References}

Association of Science and Technology Centers. (2020). Virtual science engagement. Accessed on July 28th from: https://www.astc.org/coronavirus/educationalresources/

Bannister, N. A. (2015). Reframing practice: Teacher learning through interactions in a collaborative group. Journal of the Learning Sciences, 24(3), 347-372. 
Cleveland, C. (2020). Virtual fall: America's largest school districts are opting for remote starts. Education Next. Accessed from: https://www.educationnext.org/virtual-fall-americas-largest-school-districts-areopting-for-remote-starts/

Itow, R. C. (2020). Fostering valuable learning experiences by transforming current teaching practices: Practical pedagogical approaches from online practitioners. Information and Learning Sciences.

Mishra, P., \& Koehler, M. J. (2006). Technological pedagogical content knowledge: A framework for teacher knowledge. Teachers College Record, 108(6), 1017-1054.

Nacu, D. C., Martin, C. K., Pinkard, N., \& Gray, T. (2016). Analyzing educators' online interactions: A framework of online learning support roles. Learning, Media and Technology, 41(2), 283-305.

Nacu, D., Martin, C. K., \& Pinkard, N. (2018). Designing for 21st century learning online: A heuristic method to enable educator learning support roles. Educational Technology Research and Development, 66(4), 1029-1049.

Wardrip, P. S., Gomez, L. M., \& Gomez, K. (2015). We modify each other's lessons: The role of literacy work circles in developing professional community. Teacher Development, 19(4), 445-460.

World Bank. (2020). Lessons for Education during the COVID-19 crisis. Accessed on July 30th from: https ://www.worldbank.org/en/topic/edutech/brief/lessons-for-education-during-covid-19-crisis

Publisher's Note Springer Nature remains neutral with regard to jurisdictional claims in published maps and institutional affiliations.

Peter Wardrip is an Assistant Professor of STEAM Education at the University of Wisconsin-Madison. His research focuses on designing STEAM learning activities, assessment for learning and research-practice partnerships. Peter earned his PhD in Learning Sciences and Policy from University of Pittsburgh. 